Rusanova $\mathbf{5}$.

\title{
MODELING THE COSTS OF PROJECT TRANSPORTATION MAINTENANCE
}

This study investigates variants in transportation maintenance of projects. The study subject is the mathematical notation of the dependence of costs incurred during the transportation maintenance of a project on the characteristics of maintenance options. Most projects involve a transportation component, which relates to the need to deliver raw materials, materials, equipment, manpower to the location of the product project (for example, construction projects, infrastructure projects). This study aims to identify variants in the transportation maintenance of projects, to establish mathematical dependences of transportation costs depending on the characteristics of vehicles and the conditions for their use in projects. The characteristics of the vehicles and the conditions of their operation in the projects form the essence of a specific variant of the transportation maintenance of a project. Each alternative transportation maintenance option affects the project, first of all, at the cost level. Therefore, the optimal transportation maintenance variant for a project should be selected considering the impact of options on project costs. In this study, the basis for modeling the cost of a project's transportation maintenance is the project's network schedule and an analysis of its activities in terms of the need for transportation maintenance. Mathematical expressions for the volume of transportation operations and the required number of vehicles of different types have been consistently derived. Cost dependences for three variants of vehicle utilization (rent, service, acquisition) have been derived, based on vehicle characteristics, for three levels of project consideration: certain operations, a certain time span, the project in general. The resulting formalization of transportation maintenance costs makes it possible to vary the characteristics of vehicles and the conditions for their use in a project during the decision-making phase of choosing the transportation maintenance option for a project, or their combination. The reported results underlie further development of the model for optimizing parameters and choosing the transportation maintenance variant of projects.

Keywords: vehicle utilization conditions, network project schedule, cost dependences, vehicle characteristics.

\section{Introduction}

Most projects involve the creation of new facilities (for example, construction projects, infrastructure projects) or the development of existing objects (for example, reconstruction projects), which is the essence of project products. The process of creating or transforming material objects requires appropriate materials, raw materials, components, equipment, etc., which results in the formation and functioning of a project's logistical system. The logistics of the project is relevant for those projects where a material object is created or developed, and the processes of the creation and development of a given object imply a certain system of supply, distribution, and production, associated with the material flow (flows). The existence of a logistics system necessitates the need for appropriate transportation maintenance. Thus, the transportation maintenance of a project is, in fact, the transportation maintenance of the project's logistics system. One should note that in some projects there is a need for transportation maintenance without being tied to the material flow. For example, field development projects require the delivery of workers to and from the field with a certain intensity. Moreover, in practice, such transportation of workforce is coordinated with the delivery of products, certain types of equipment, etc. For example, in offshore field development projects, the delivery of workers by tug is carried out along with the delivery of products. Therefore, providing such a project with manpower should be carried out inextricably with the functioning of the logistics system, providing the workforce forms a specific material flow, and their transportation is part of the transportation maintenance of the project's logistics. Therefore, it is a relevant task to investigate the issue of transportation maintenance of projects and to form a theoretical basis for substantiating the fleet of vehicles for projects and the conditions for their utilization within a project.

\section{The object of research and its technological audit}

The object of this study is the options for the transportation maintenance of projects. The characteristics of vehicles and the conditions of their operation within a project form the essence of a specific variant of the transportation maintenance of the project. Each alternative transportation maintenance option affects the project, first of all, at the level of costs. In addition, each transportation maintenance variant is associated with certain risks, which are also manifested in the form of risks to the entire project. Therefore, choosing the optimal transportation maintenance variant for a project should consider the impact of the options 
on project costs. The main approach of this study is to consider and study the transport costs of the project in the context of the project rather than individual transportation processes. At the same time, transportation maintenance can be considered at three levels: at the level of separate operation within the network schedule of the project, at the level of a specific period within the life cycle of the project, and at the project level in general.

One of the issues in the formation of transportation maintenance of projects is the establishment of its impact on the project in general, both at the level of costs and at the level of risks. Therefore, when examining the transportation maintenance of projects, the focus should be on the patterns of transportation costs for the project in general.

\section{The aim and objectives of research}

The aim of this study is to model the costs of alternative variants of transportation maintenance for projects.

To accomplish the aim, the following tasks have been set:

1. Identify and characterize basic transportation maintenance variants for projects.

2. Describe mathematically the formation of the volume of transport operations for a project at the levels of specific activity, time span, and project in general.

3. Establish cost-forming patterns for the project's alternative transportation maintenance options.

\section{Research of existing solution of the problem}

Choosing the optimal transportation maintenance and optimizing the parameters of transportation maintenance are classic tasks for logistics and transport. Most of the approaches used are based on stock theory [1, 2], which integrates the delivery and storage within a single system, which is typical of logistics. Some studies tackle the minimization of transport costs considering the conditions for vehicle selection [3,4]. Several works address the optimization of transportation costs by varying delivery technology $[5,6]$.

A project, unlike delivery systems or logistics systems, is a very specific object, and, accordingly, the transportation maintenance of projects has a certain specificity. However, one should note that this issue is almost unexplored in the modern scientific literature. All publications in this area can be divided into two categories. The first includes works related directly to transportation (for example, [7]) and logistics (for example, [8]) projects. Typically, these works are based on a cost management review of these projects [9], or their organizational problems [10]. The basic provisions of the transport project management methodology are presented in [11]. The management of the life cycle of transport projects, taking into consideration their specificity, is considered in [12]. The second category of research (for example, $[13,14$ ) addresses the maintenance of field development projects. The focus of such studies is either a service schedule [14] or the optimization of service processes in terms of routes [15]. In addition, in some studies, transportation is considered as a project, that is, a design-oriented approach to cargo delivery is used [16]. The cited work examines transportation parameters as a result of the implementation of projects or part of their product. Typically, these studies address the transportation of materials, products, and equipment during the platform operation phase. In fact, the transportation maintenance of logistics for existing project products is being considered, which determines the task of transportation maintenance similar to traditional transportation tasks for logistics systems.

However, transportation maintenance is also used to obtain a product project, affecting its cost and timing. The approach to transportation maintenance considering not only the parameters of vehicles (sea vessels in that case) but the conditions of their utilization (acquisition, rent, chartering for a cruise) was proposed in $[4,5]$. Such an approach can be transferred to projects of various kinds, taking into consideration universalization (that is, for different modes of transport used in the project).

\section{Methods of research}

The subject of this study is a mathematical notation of the dependence of the transportation maintenance cost of a project on the characteristics of maintenance variant.

The study methods. This study was carried out in accordance with the principles and methodology of general systems theory. The analysis and synthesis techniques were used to identify the transportation maintenance variants for projects. Functional analysis was applied to formalize the transportation maintenance cost of projects for the options.

\section{Research results}

6.1. Alternative variants of project transportation maintenance. In terms of project management, transportation maintenance options relate primarily to the project, that is, the terms of using them in the project. There are three such basic options. Transportation services for the project can be rendered by third-party organizations, that is, transportation services are delivered from «out of the project» in accordance with the necessary parameters (which corresponds to the area of knowledge «procurement management»). The second option is to attract vehicles on lease terms for the required period. Examples include the rental of tugs and ships of universal purpose to service offshore field development projects: vessels supply equipment and individual elements of mining platforms. Tugs deliver food and people. As a rule, vessels on such projects operate on the terms of the time-charter lease - rent over a period, at which the cost of the project includes all variable costs related to vessels. The third option of project transportation maintenance is the use of the company's vehicles, including the purchase of vehicles for the project. One should note that unlike projects to purchase ships (other vehicles), the purchase of vessels (vehicles) «for the project» may form a sub-project in large-scale projects. In this case, the main purpose of the acquisition is not to profit from ships' activities but to provide transportation maintenance for the project, as well as to reduce transportation costs of the project and improve control over transport processes. The transportation maintenance options for a project are shown in Fig. 1. There are also the main pros and cons of these variants.

One should note that the advantages of rental and acquisition of vehicles are that they can be used for other projects during the implementation of the project considered; purchased vehicles - for other projects in the future. In particular, this is relevant for design-oriented companies if the essence of most projects is related to the need for transportation. 


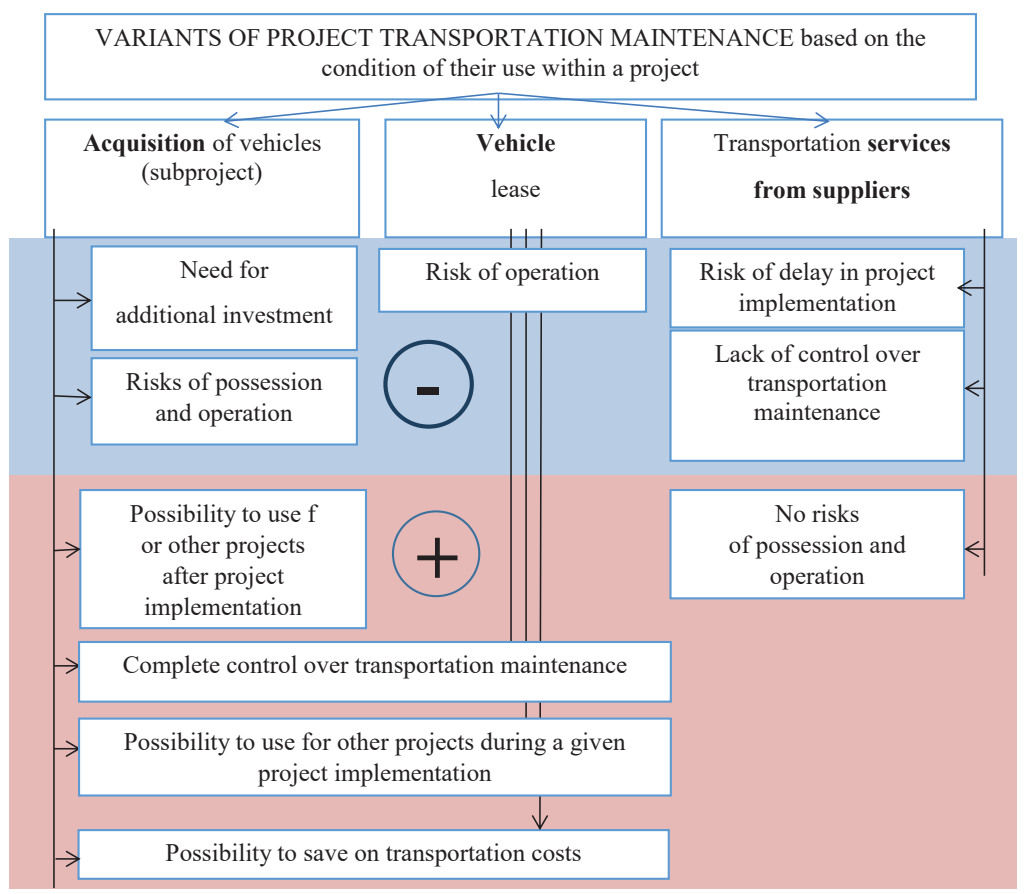

Fig. 1. Transportation maintenance options based on the condition of vehicle utilization in the project

Typically, projects require the use of different types of vehicles (for example, road transport, water transport), vehicle type index is $k=\overline{1, K}$. Moreover, the need may arise in different types of vehicles of each type (for example, vehicles with a body, container vehicles, etc., marine tugs of varying power, and cargo ships of varying payload capacity). Designate the options for these types:

$$
g=\overline{1, G_{k}}
$$

where $G_{k}, k=\overline{1, K}$ is the number of types of vehicles of each type. Each type of vehicle may have a variety of characteristics (such as engine power, payload capacity in certain limits, etc.) In addition, the vehicle is characterized by the manufacturer (brand), age. Designate the totality of the vehicle's characteristics as:

$$
C_{k}^{g}=\left(C_{k 1}^{g}, C_{k 2}^{g}, \ldots, C_{k Y_{k}}^{g}\right),
$$

where $Y_{k}$ is the number of characteristics of a particular type of vehicle under consideration.

Designate the options for using vehicles:

$$
b=1,2,3 \text {, }
$$

where $b=1$ is the purchase of a vehicle; $b=2$ is the rent of a vehicle; $b=3$ is the transportation services as a service from suppliers (Fig. 2). Thus, the alternative project transportation maintenance variant is the vehicle itself, a specific type, type with specific characteristics, and specific conditions of its utilization in the project. All the above (the type, kind, characteristics of the vehicle, and the conditions of its use in the project) affects the cost of using a particular variant of transportation maintenance and the characteristics of the project in general.

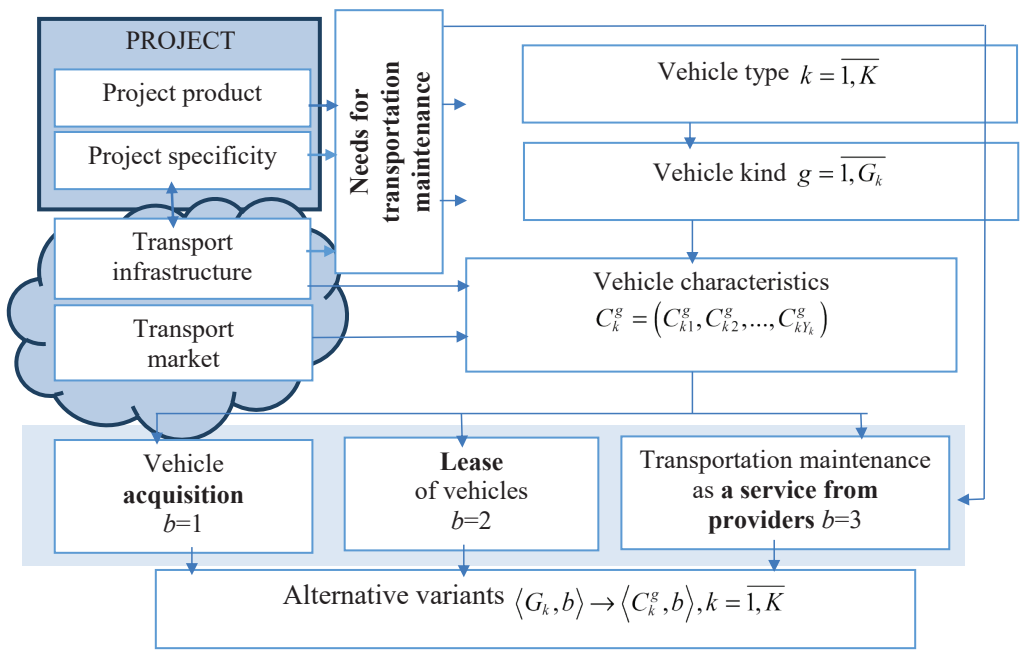

Fig. 2. Alternative options for project transportation maintenance

One should note that the transport infrastructure and the transportation services market set certain restrictions on the formation of alternative options.

The above scheme illustrating the formation of alternative transportation maintenance options is the basis for deciding on the choice of specific variants for a particular project, taking into consideration its specificity.

6.2. Determining the volume of transport operations in the project (transportation services in the project). This phase identifies design work and time periods requiring transport services with differentiation by mode of transportation. At the same time, it is necessary to establish the interchangeability of different types and kinds of vehicles. For example, buses of varying passenger capacity can deliver workers to the site of project operations, or tugs of varying capacity can be involved in projects related to water infrastructure or field development. 
The basis for determining the volume of transport services in the project is a network schedule. The correlation of transport-requiring operations along a temporal axis makes it possible to allocate the volumes and periods of time for transportation maintenance by the type and kind of vehicles (Fig. 3).
Thus:

- $Q_{k i j}^{g}$ characterizes the amount of transport services for the specific activity of the project for each type and kind of vehicle used in the project;

- $Q_{k}^{g}\left(t_{\alpha_{\tau}}, t_{\beta_{\tau}}\right)$ is the volume of transport services for the project over a specific period $\left[t_{\alpha_{\tau}}, t_{\beta_{\tau}}\right]$, where:

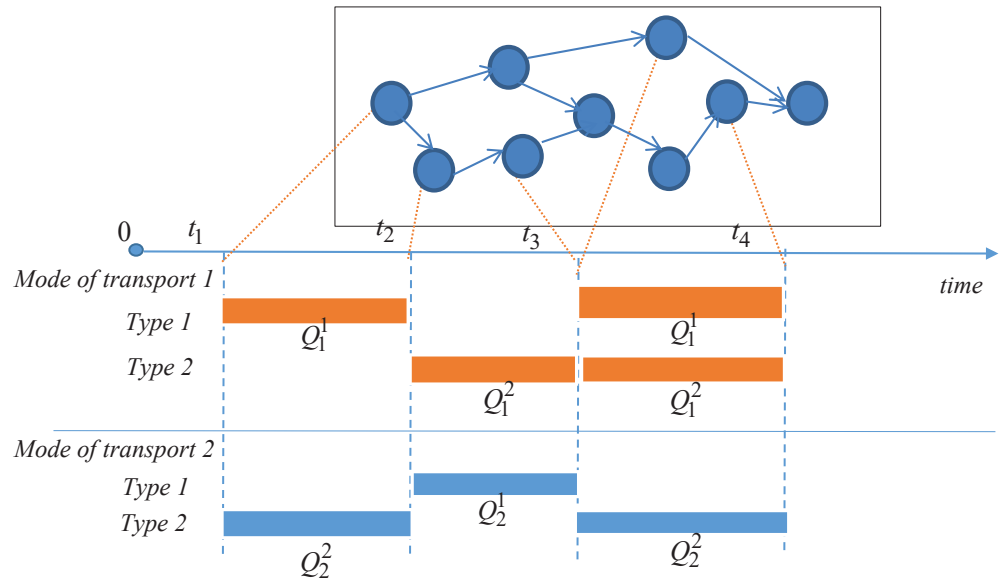

Fig. 3. Determining the volume of transport operations in a project

$$
\bigcup_{\tau=1}^{\psi}\left[t_{\alpha_{\tau}}, t_{\beta_{\tau}}\right] \subset T
$$

that is, the allocated intervals involving transportation services are «overlapped» by the life cycle of project $T ; Q_{k}^{* g}$ is the total volume of transportation services for the project with a specific type and kind of mode of transport.

6.3. Identification of the number of vehicles based on operations, time intervals of the project in general. At this stage, the number of vehicles of each type and kind required is determined, taking into consideration the specific conditions of each project activity.

As mentioned above, vehicles with different characteristics $C_{k}^{g}=\left(C_{k 1}^{g}, C_{k 2}^{g}, \ldots, C_{k Y_{k}}^{g}\right)$ can be used for each type of transportation, which allows for a certain variation in the project. Thus, for each allocated time span $\left[t_{\alpha_{\tau}}, t_{\beta_{\tau}}\right]$ and each type/kind of vehicle, certain boundaries of variance in its characteristics are set:

$$
\begin{aligned}
& C_{k y}^{g \min }\left(t_{\alpha_{\tau}}, t_{\beta_{\tau}}\right) \leq C_{k y}^{g}\left(t_{\alpha_{\tau}}, t_{\beta_{\tau}}\right) \leq C_{k y}^{g \max }\left(t_{\alpha_{\tau}}, t_{\beta_{\tau}}\right), \\
& k=\overline{1, K}, g=\overline{1, G_{k}}, y=\overline{1, Y_{k}}, \tau=\overline{1, \psi},
\end{aligned}
$$

where $C_{k y}^{g \min }, C_{k y}^{g \max }$ are the acceptable variance limits. Alternatively, similar requirements are set for each specific operation involving transportation services:

$$
\begin{aligned}
& C_{k y j}^{g \min } \leq C_{k y j j}^{g} \leq C_{k y i j}^{g \max }, \\
& k=\overline{1, K}, g=\overline{1, G_{k}}, y=\overline{1, Y_{k}}, i=\overline{1, n-1}, j=\overline{2, n} .
\end{aligned}
$$

One should note that, as previously determined, transport services can be considered on the basis of an operation within project $A_{i j}$, or based on the time intervals $\left[t_{\alpha_{\tau}}, t_{\beta_{\tau}}\right]$ within the life cycle of the project. The approach to consideration is conditioned by the specificity of the project - thus, if the project operation of one period has specific requirements for transportation services, and they are significantly different from each other, then, in this situation, the most appropriate consideration is based on operations. If the transportation services for the operation within a single time period do not differ significantly in terms of requirements for the characteristics of a particular type and kind of vehicle, it would be appropriate to consider the transportation services in an integrated fashion based on time periods.

The characteristics of a vehicle define its «performance» $P_{k i j}^{g}$ (carrying capacity) under the specific conditions of the transportation services in question (the distance of transportation, in particular): 


$$
\begin{aligned}
& P_{k i j}^{g}=P_{k i j}^{g}\left(C_{k}^{g}, A_{k i j}^{g}\right)=P_{k i j}^{g}\left(C_{k 1}^{g}, C_{k 2}^{g}, \ldots, C_{k Y_{k}}^{g}, A_{k i j 1}^{g}, A_{k i j 2}^{g}, \ldots, A_{k i j W_{k}^{g}}^{g}\right), \\
& k=\overline{1, K}, g=\overline{1, G_{k}}, y=\overline{1, Y_{k}}, i=\overline{1, n-1}, j=\overline{2, n},
\end{aligned}
$$

where $A_{k i j}^{g}=\left(A_{k i j 1}^{g}, A_{k i j 2}^{g}, \ldots, A_{k j \mid}^{g} W_{k}^{g}\right)$ is the project $A_{i j}$ operation characteristics in terms of rendering a transport service by the mode of transport $k$, the type of vehicle $g ; W_{k}^{g}$ is the number of assigned characteristics of project operations in terms of transport services (primarily, the distance of transportation, empty/ballast trips/transitions, loading/unloading intensity, the need for additional stops, etc.). Under the fixed conditions $A_{k i j}^{g}$, the vehicle's carrying ability is determined by its characteristics, that is $P_{k i j}^{g}\left(C_{k}^{g}\right)$.

Vehicle operational performance (carrying capacity) $P_{k i j}^{g}\left(C_{k}^{g}\right)$ determines the number of vehicles of each type and kind $N_{k i j}^{g}$ required to perform transport services for the project operations:

$$
\begin{aligned}
& N_{k i j}^{g}\left(C_{k}^{g}\right)=\frac{Q_{k i j}^{g}}{P_{k i j}^{g}\left(C_{k}^{g}\right)}, \\
& k=\overline{1, K}, g=\overline{1, G_{k}}, i=\overline{1, n-1}, j=\overline{2, n} .
\end{aligned}
$$

Note that the number of vehicles required depends on their characteristics. At the level of specific activity, $N_{k i j}^{g}$ is not rounded. In order to avoid redundancy in determining the total number of vehicles as a result of rounding, it makes sense to perform this procedure as part of the integration of transport services based on time periods and the project in general.If the conditions of transportation services for operations within a single time period $\left[t_{\alpha_{\tau}}, t_{\beta_{\tau}}\right]$ are almost the same, that is $P_{k i j}^{g}=P_{k}^{g}$, $A_{i j} \in\left[t_{\alpha_{\tau}}, t_{\beta_{\tau}}\right]$ :

$$
N_{k}^{\prime g}\left(t_{\alpha_{\tau}}, t_{\beta_{\tau}}\right)=\left\lceil\frac{Q_{k}^{g}\left(t_{\alpha_{\tau}}, t_{\beta_{\tau}}\right)}{P_{k}^{g}\left(t_{\alpha_{\tau}}, t_{\beta_{\tau}}\right)}\right\rceil, k=\overline{1, K}, g=\overline{1, G_{k}}, \tau=\overline{1, \psi} .
$$

In this case, the carrying ability naturally depends on $\left[t_{\alpha_{\tau}}, t_{\beta_{\tau}}\right]$. (9) gives rounded values on time stages, which is appropriate for long-term projects and, accordingly, for long periods $\left[t_{\alpha_{\tau}}, t_{\beta_{\tau}}\right]$. Given that the characteristics of the vehicle determine its carrying capacity $P_{k}^{g}$, then (9) can be represented as:

$$
\begin{aligned}
& N_{k}^{g \prime \prime}\left(C_{k}^{g}, t_{\alpha_{\tau}}, t_{\beta_{\tau}}\right)=\left\lceil\frac{Q_{k}^{g}\left(t_{\alpha_{\tau}}, t_{\beta_{\tau}}\right)}{P_{k}^{g}\left(C_{k}^{g}, t_{\alpha_{\tau}}, t_{\beta_{\tau}}\right)}\right\rceil, \\
& k=\overline{1, K}, g=\overline{1, G_{k}}, \tau=\overline{1, \psi} .
\end{aligned}
$$

The total number of vehicles of each type and kind for a project in general:

$$
\begin{aligned}
& N_{k}^{* g}\left(C_{k}^{g}\right)=\left\lceil\sum_{i=1}^{n-1} \sum_{j=2}^{n} N_{k i j}^{g}\left(C_{k}^{g}\right)\right], k=\overline{1, K}, g=\overline{1, G_{k}}, \\
& N_{k}^{* g}\left(C_{k}^{g}\right)=\left\lceil\sum_{\tau=1}^{\psi} N_{k}^{g}\left(C_{k}^{g}, t_{\alpha_{\tau}}, t_{\beta_{\tau}}\right)\right], k=\overline{1, K}, g=\overline{1, G_{k}} .
\end{aligned}
$$

Thus, (11) reflects the total number of vehicles for the project, taking into consideration the information for each project activity $A_{i j}$; (12) - taking into consideration the information about the time spans of the project life cycle $\left[t_{\alpha_{\tau}}, t_{\beta_{\tau}}\right]$.
6.4. Determining the cost of transportation services for project operations. At this stage, the cost characteristics of transportation services are determined for the alternative options of transportation maintenance.

As defined above, the alternative character is primarily in the characteristics of the vehicles and their uses in the project, that is, the characteristics of the vehicle affect the cost of utilization, the cost of purchase, and the cost of rent.

If project transportation maintenance involves the use of transport services from suppliers, that is, $b=3$, the costs $R_{k b}^{g}$ depend on the volume of transport services and characteristics of vehicles. For each operation, the costs are:

$$
\begin{aligned}
& R_{k b i j}^{g}=R_{k b i j}^{g}\left(C_{k}^{g}, Q_{k i j}^{g}\right), \\
& b=3, k=\overline{1, K}, g=\overline{1, G_{k}}, i=\overline{1, n-1}, j=\overline{2, n},
\end{aligned}
$$

- for the totality of operations within a time interval $\left[t_{\alpha_{\tau}}, t_{\beta_{\tau}}\right]$ :

$$
\begin{aligned}
& R_{k b}^{g}\left(t_{\alpha_{\tau}}, t_{\beta_{\tau}}\right)=R_{k b}^{g}\left(C_{k}^{g}, Q_{k}^{g}, t_{\alpha_{\tau}}, t_{\beta_{\tau}}\right), \\
& b=3, k=\overline{1, K}, g=\overline{1, G_{k}}, \tau=\overline{1, \psi} ;
\end{aligned}
$$

- for the entire project:

$$
R_{k b}^{* g}=R_{k b}^{* g}\left(C_{k}^{g}, Q_{k}^{* g}\right), b=3, k=\overline{1, K}, g=\overline{1, G_{k}} .
$$

If the transportation maintenance implies the rental of vehicles, that is, $b=2$, then, in addition to the characteristics of vehicles, the costs depend on the number of vehicles rented and the length of their lease. At the same time, the lease term $T_{k}^{g}$ may be the duration $t_{i j}$ of the project operation $A_{i j}$, the period of time $\left[t_{\alpha_{\tau}}, t_{\beta_{\tau}}\right]$, or the entire period of the active phase of the life cycle of the project (that is, the period of time when the project logistics system is functioning or transportation-related operations are performed). The costs in this situation for a particular operation are:

$$
\begin{aligned}
& R_{k b i j}^{g}=R_{k b i j}^{g}\left(C_{k}^{g}, Q_{k i j}^{g}, t_{i j}\right), T_{k}^{g}=t_{i j}, \\
& b=2, k=\overline{1, K}, g=\overline{1, G_{k}}, i=\overline{1, n-1}, j=\overline{2, n},
\end{aligned}
$$

- for the totality of operations within a time pe$\operatorname{riod}\left[t_{\alpha_{\tau}}, t_{\beta_{\tau}}\right]$ :

$$
\begin{aligned}
& R_{k b}^{g}\left(t_{\alpha_{\tau}}, t_{\beta_{\tau}}\right)=R_{k b}^{g}\left(C_{k}^{g}, Q_{k}^{g}, t_{\alpha_{\tau}}, t_{\beta_{\tau}}\right), \\
& T_{k}^{g}=t_{\beta_{\tau}} t_{\alpha_{\tau}}, b=2, k=\overline{1, K}, g=\overline{1, G_{k}}, \tau=\overline{1, \psi} ;
\end{aligned}
$$

- for the entire project:

$$
R_{k b}^{* g}=R_{k b}^{* g}\left(C_{k}^{g}, Q_{k}^{* g}, T_{k}^{g}\right), b=2, k=\overline{1, K}, g=\overline{1, G_{k}} .
$$

When renting a vehicle, the costs include operating expenses $R_{k b}^{o g}$ and actual rental fees $R_{k b}^{r g}$. Both depend on the characteristics of a vehicle; operating expenses also depend on the volume of transport services. Considering (16) to (18) accounting for that makes it possible to obtain the following:

$$
\begin{aligned}
& R_{k b i j}^{g}=R_{k b i j}^{g}\left(C_{k}^{g}, Q_{k i j}^{g}, t_{i j}\right)=R_{k b i j}^{o g}\left(C_{k}^{g}, Q_{k i j}^{g}\right)+R_{k b i j}^{r g}\left(C_{k}^{g}, t_{i j}\right), \\
& T_{k}^{g}=t_{i j}, b=2, k=\overline{1, K}, g=\overline{1, G_{k}}, i=\overline{1, n-1}, j=\overline{2, n} ;
\end{aligned}
$$




$$
\begin{aligned}
& R_{k b}^{g}\left(t_{\alpha_{\tau}}, t_{\beta_{\tau}}\right)=R_{k b}^{g}\left(C_{k}^{g}, Q_{k}^{g}, t_{\alpha_{\tau}}, t_{\beta_{\tau}}\right)= \\
& =R_{k b}^{o g}\left(C_{k}^{g}, Q_{k}^{g}\right)+R_{k b}^{r g}\left(C_{k}^{g}, t_{\alpha_{\tau}}, t_{\beta_{\tau}}\right), \\
& T_{k}^{g}=t_{\beta_{\tau}} t_{\alpha_{\tau}}, b=2, k=\overline{1, K}, g=\overline{1, G_{k}}, \tau=\overline{1, \psi} ; \\
& R_{k b}^{* g}=R_{k b}^{* g}\left(C_{k}^{g}, Q_{k}^{* g}, T_{k}^{g}\right)= \\
& =R_{k b}^{* o g}\left(C_{k}^{g}, Q_{k}^{* g}\right)+R_{k b}^{* r g}\left(C_{k}^{g}, T_{k}^{g}\right), \\
& b=2, k=\overline{1, K}, g=\overline{1, G_{k}} .
\end{aligned}
$$

Note that the cost of renting vehicles is defined as follows:

- for an operation:

$$
\begin{aligned}
& R_{k b i j}^{r g}\left(C_{k}^{g}, t_{i j}\right)=f_{k}^{r g}\left(C_{k}^{g}, t_{i j}\right) \cdot N_{k i j}^{g}\left(C_{k}^{g}\right) \cdot t_{i j}, \\
& b=2, k=\overline{1, K}, g=\overline{1, G_{k}}, i=\overline{1, n-1}, j=\overline{2, n} ;
\end{aligned}
$$

- for a time period:

$$
\begin{aligned}
& R_{k b}^{r g}\left(C_{k}^{g}, t_{\alpha_{\tau}}, t_{\beta_{\tau}}\right)=f_{k}^{r g}\left(C_{k}^{g}, t_{\alpha_{\tau}}, t_{\beta_{\tau}}\right) \cdot N_{k}^{g}\left(C_{k}^{g}, t_{\alpha_{\tau}}, t_{\beta_{\tau}}\right) \cdot\left(t_{\beta_{\tau}}, t_{\alpha_{\tau}}\right), \\
& b=2, k=\overline{1, K}, g=\overline{1, G_{k}}, \tau=\overline{1, \psi} ;
\end{aligned}
$$

- for the entire project in general:

$$
\begin{aligned}
& R_{k b}^{* r g}\left(C_{k}^{g}, T_{k}^{g}\right)=f_{k}^{r g}\left(C_{k}^{g}, T_{k}^{g}\right) \cdot N_{k}^{* g}\left(C_{k}^{g}\right) \cdot T_{k}^{g}, \\
& b=2, k=\overline{1, K}, g=\overline{1, G_{k}},
\end{aligned}
$$

where $f_{k}^{r g}\left(C_{k}^{g}, t_{i j}\right), f_{k}^{r g}\left(C_{k}^{g}, t_{\alpha_{\tau}}, t_{\beta_{\tau}}\right), f_{k}^{r g}\left(C_{k}^{g}, T_{k}^{g}\right)$ are, respectively, the vehicle rental rates.

If the project is supposed to purchase vehicles, that is, $b=1$, then, in addition to operating (operational) costs, which are determined by the characteristics of the vehicle, the project costs would include fixed costs and expenses associated with the acquisition $R_{k b}^{i n v g}$ - investment costs. The latter depends on the characteristics of the vehicle and the terms of purchase $F=\left(F_{1}, . ., F_{\lambda}\right)$, where the components can be, for example, the interest rate, the term of the loan, the terms of repayment of the loan, the share of own funds.

In this situation, the cost of transportation maintenance is:

- for a period:

$$
\begin{aligned}
& R_{k b}^{g}\left(t_{\alpha_{\tau}}, t_{\beta_{\tau}}\right)=R_{k b}^{g}\left(C_{k}^{g}, Q_{k}^{g}, t_{\alpha_{\tau}}, t_{\beta_{\tau}}, F\right)= \\
& =R_{k b}^{o g}\left(C_{k}^{g}, Q_{k}^{g}\right)+R_{k b}^{p g}\left(C_{k}^{g}, t_{\alpha_{\tau}}, t_{\beta_{\tau}}\right)+R_{k b}^{i n v g}\left(C_{k}^{g}, F\right), \\
& b=1, k=\overline{1, K}, g=\overline{1, G_{k}}, \tau=\overline{1, \psi} ;
\end{aligned}
$$

- for the project in general:

$$
\begin{aligned}
& R_{k b}^{* g}=R_{k b}^{* g}\left(C_{k}^{g}, Q_{k}^{* g}, T_{k}^{g}, F\right)= \\
& =R_{k b}^{* 0 g}\left(C_{k}^{g}, Q_{k}^{* g}\right)+R_{k b}^{* p g}\left(C_{k}^{g}, T_{k}^{g}\right)+R_{k b}^{* i n v g}\left(C_{k}^{g}, F\right), \\
& b=1, k=\overline{1, K}, g=\overline{1, G_{k}} .
\end{aligned}
$$

In practice, the purchase of vehicles as transportation maintenance for individual operations within a project is not executed unless it is a large-scale project and aggregated operations. For example, if the installation of equipment in field development projects is an activity, transportation maintenance is required during these activities, both for the delivery of equipment and materials and for the delivery of personnel. In such situations, an estimate of the cost of transportation maintenance, involving the purchase of vehicles, is appropriate:

$$
\begin{aligned}
& R_{k b i j}^{g}=R_{k b i j}^{g}\left(C_{k}^{g}, Q_{k i j}^{g}, t_{i j}, F\right)= \\
& =R_{k b i j}^{o g}\left(C_{k}^{g}, Q_{k i j}^{g}\right)+R_{k b i j}^{p g}\left(C_{k}^{g}, t_{i j}\right)+R_{k b i j}^{i n v g}\left(C_{k}^{g}, F\right), \\
& b=1, k=\overline{1, K}, g=\overline{1, G_{k}}, i=\overline{1, n-1}, j=\overline{2, n} .
\end{aligned}
$$

Note that in order to correctly estimate the cost of transportation maintenance for the project at $b=1$, the term of the loan (if any is used) must be within the life cycle of the project. Otherwise, the vehicle is used in other projects, which is important and is the case for project-oriented companies that invest in transport means to implement a whole portfolio of projects over a period.

\section{SWOT analysis of research results}

Strengths. This paper focuses on the structuring of the transport component of projects based on operations and time interval. In this study, the basis for modeling the cost of project transportation maintenance is a network project schedule and an analysis of its operations in terms of the need for transportation maintenance. Mathematical expressions for the volume of transport operations and the required number of vehicles of different kinds have been consistently derived. Cost dependences for three vehicle utilization options (rent, service, acquisition) based on vehicle characteristics have been established for three levels of project consideration: certain operations, a certain time span, the project in general. Thus, in contrast to available studies, this work has structured transportation maintenance in accordance with the structure of the project. This provides a practical tool for project management based on the appropriate system of transport characteristics in volume and monetary terms.

Weaknesses. The weakness of the reported results is that they are general in nature, and the resulting formalizations do not take into consideration the specificity of patterns for particular types and kinds of vehicles. This determines the need for statistical industry research to establish the required dependences.

Opportunities. The formalization of transportation maintenance costs makes it possible to vary the characteristics of vehicles and their conditions of use in a project during the decision-making phase of choosing an option of the project transportation maintenance or the formation of their combination. In addition, formalization of risks, quality, and value, carried out by analogy, could complement the characteristics of alternative options for project transportation maintenance. Thus, the reported results are the basis for further development of the model for optimizing parameters and choosing the transportation maintenance option for projects or forming their optimal combination. This could result in the solution to obtain the required project transportation maintenance that would meet all the requirements for the project in terms of its characteristics, such as costs, value, risks.

Threats. There are virtually no threats to this study, as most projects involve transportation maintenance; in this case, the network schedule, to which the necessary transportation volumes are tied, is an unchanged basis for structuring the project. 


\section{Conclusions}

1. The result of the generalization of practical experience and the theoretical base is the identified alternative transportation maintenance options for projects, described at a meaningful level. These variants correspond to the specific parameters of specific types and kinds of vehicles, as well as one of the conditions for their use in the project - acquisition, rental, service from project suppliers. The positive and negative aspects of different conditions of vehicle utilization in a project have been revealed.

2. A method has been developed to establish the necessary volumes of transportation operations within a project for three levels: at the level of specific activity, a time span, and a project in general. The basis for formalizing was the network schedule of the project, the analysis of the transportation requirements from individual operations, and its comparison with the life cycle of the project.

3. Formalizations have been obtained in the form of theoretical dependences of costs on the alternative options of project transportation maintenance. Underlying the formalization is the dependence of the transportation capacity of vehicles and various cost components (for three types of vehicle application in a project) on the vehicle parameters.

\section{References}

1. Shepelev, V., Almetova, Z., Larin, O., Shepelev, S., Issenova, O. (2018). Optimization of the Operating Parameters of Transport and Warehouse Complexes. Transportation Research Procedia, 30, 236-244. doi: http://doi.org/10.1016/j.trpro.2018.09.026

2. Liu, Q., Min, H. (2008). A Collaborative Production Planning Model for Multi-Agent Based Supply Chain. Proceedings - International Conference on Computer Science and Software Engineering, 1, 512-515. doi: http://doi.org/10.1109/csse.2008.543

3. Chen, Z., Liang, Y., Wu, Y., Sun, L. (2019). Research on Comprehensive Multi-Infrastructure Optimization in Transportation Asset Management: The Case of Roads and Bridges. Sustainability, 11 (16), 4430. doi: http://doi.org/10.3390/su11164430

4. Onischenko, S. P., Siraev, A. R., Samoilovskaia, V. P. (2012). Estimation of efficiency of transportation organization of distribution systems. Eastern-European Journal of Enterprise Technologies, 6 (3(60)), 37-43. Available at: http://journals.uran.ua/ eejet/article/view/5509
5. Onyshchenko, S., Siraev, A. (2013) Optimization of transport support for distribution systems of export products. Methods for managing the development of transport systems, 1, 58-72.

6. Rusanova, S., Onyshchenko, S. (2020). Development of transport and technological process options' concept for goods delivery with participation of maritime transport. Technology audit and production reserves, 1 (2 (51)), 24-29. doi: http://doi.org/ $10.15587 / 2312-8372.2020 .198373$

7. Gamez, E. A., Touran, A. (2009). A Method of Risk ranking for International Transportation Projects. Proceedings of 7th International Probabilistic Workshop. Delft, 187-203.

8. Andrievska, V., Bondar, A., Onyshchenko, S. (2019) Identification of creation and development projects of logistic systems. Development of management and entrepreneurship methods on transport, 4 (69), 26-37.

9. Owens, J. (2010). Project Management for Complex Transportation Projects. Graduate Theses and Dissertations, 11627. doi: http://doi.org/10.31274/etd-180810-1807

10. Guidance for Transportation Project Management (2009). National Academies of Sciences, Engineering, and Medicine. Washington: The National Academies Press. doi: http://doi.org/10.17226/23028

11. Bínová, H. (2013). Methodology of transportation project management. Journal of System of Integration, 1, 30-37.

12. Abou-Senna, H., Radwan, E., Navarro, A., Abdelwahab, H. (2018). Integrating transportation systems management and operations into the project life cycle from planning to construction: A synthesis of best practices. Journal of Traffic and Transportation Engineering (English Edition), 5 (1), 44-55. doi: http://doi.org/10.1016/j.jtte.2017.04.006

13. Halvorsen-Weare, E. E., Fagerholt, K. (2011). Robust Supply Vessel Planning. Network Optimization. Berlin: Springer, 559-573. doi: http://doi.org/10.1007/978-3-642-21527-8 62

14. Halvorsen-Weare, E. E., Fagerholt, K. (2010). Routing and scheduling in a liquefied natural gas shipping problem with inventory and berth constraints. Annals of Operations Research, 203 (1), 167-186. doi: http://doi.org/10.1007/s10479-010-0794-y

15. Welte, T. M., Sperstad, I. B., Halvorsen-Weare, E. E., Netland, Ø., Nonås, L. M., Stålhane, M. (2018). Operation and maintenance modelling. Offshore Wind energy technology, 269-303. doi: http:// doi.org/10.1002/9781119097808.ch7

16. Pavlova, N., Onyshchenko, S. (2020). Organization Of Transport Company's Project-Oriented Management (on the Example of the Freight Forwarding Company). Management of Development of Complex Systems, 42, 23-28. doi: http://doi.org/ 10.32347/2412-9933.2020.42.23-28

Rusanova Svitlana, Assistant, Department of Port Operating and Handling Technologies, Odessa National Maritime University, Odessa, Ukraine, e-mail: rusanova20140909@gmail.com, ORCID: http:// orcid.org/0000-0003-3624-6582 